\title{
Complete Rockall Score in Predicting Outcomes in Acute Upper Gastrointestinal Bleeding
}

\author{
Khus Raj Dewan, ${ }^{1}$ Bhanumati Saikia Patowary, ${ }^{2}$ Subash Bhattarai, ${ }^{3}$ Gaurav Shrestha ${ }^{4}$ \\ ${ }^{1}$ Department of Gastroenterology and Hepatology, College of Medical Sciences-Teaching Hospital, Bharatpur-10, \\ Chitwan, Nepal.
}

\begin{abstract}
Background: Acute upper GI bleeding is a common medical emergency with a hospital mortality of approximately $10 \%$. Higher mortality rate is associated with re-bleedinging. Complete Rockall scoring system identifies patients at higher risk of re-bleeding and mortality. Materials and Methods: This is a descriptive hospital based study conducted in Gastroenterology unit of College of Medical Sciences and Teaching Hospital, Bharatpur, Nepal from January 2012 to December 2014. It included 200 patients at random presenting with manifestations of UGI bleed. Complete Rockall score was calculated in each patient and its correlation with mortality and re-bleeding was determined. Scores of $\geq 5$ has been considered as one category as it comprises of patients with very high risks and scores of 0-4 as another category of low or lesser risks for the purpose of comparison of different risk factors. Results: Males were predominant (71\%). Age ranged from 14 to 90 years, mean being $50.43 \pm 17.75$ years. At presentation 110 patients $(55 \%)$ had both hematemesis and malena, 56 patients $(28 \%)$ had only malena and 34 patients (17\%) had only hematemesis. Shock was detected in $21 \%$, severe anemia and high blood urea were found in $31 \%$ and $41 \%$ respectively. Median hospital stay was $6.5 \pm 3.10$ days. Comorbidities were present in $83.3 \%$. Complete Rockall score ranged from 0 to 9 , mean being $4.30 \pm 2.19$. One hundred and thirteen $(56.5 \%)$ had complete Rockall score $\leq 4$ and $87(43.5 \%) \geq 5$. Re-bleeding was found in $16(8 \%)$ patients. One hundred and eighty eight patients $(94 \%)$ recovered and discharged from the hospital and 12 patients $(6 \%)$ expired. The correlations between high Rockall scores $(\geq 5)$ and the occurrence of re-bleeding $(\mathrm{p}=0.001)$ and mortality $(\mathrm{p}=0.001)$ were statistically significant. Conclusions: Acute Upper GI bleeding is a medical emergency. Predictors of mortality in this series were high complete Rockall score $\geq 5$, esophageal varices with Child Pugh score $C$, massive initial bleed as well as re-bleed and multiple co-morbidities.
\end{abstract}

Keywords: acute upper gastrointestinal bleed; complete Rockall score; co-morbidities; re-bleed; mortality.

\section{INTRODUCTION}

Acute upper gastrointestinal bleeding (AUGIB) represents a common emergency, with a mortality rate of $7 \%$ to $10 \%{ }^{1}$ Despite the advances in therapeutic management, re-bleeding is considered the most important risk factor for mortality and occurs in $10 \%$ to $30 \%$ of those successfully treated. $^{2}$

Various tools have been described for the prediction of outcome of the patients with AUGIB. In 1993, the Rockall Scoring system was introduced to predict the mortality and was validated for its use to identify the patients at high risk for re-bleed and mortality. Complete Rockall scoring system is based on an initial clinical score at the time of admission which consist of age (score 0-2), presence of shock (0-2), co-morbidities (score 0-3) and post endoscopic diagnosis (score 0-2) with stigmata of recent hemorrhages (score 0-2). Both clinical and post endoscopic scores added together gives a complete Rockall score with maximum possible score being $11 .^{3}$

This article aims to describe the patients of AUGIB in terms of complete Rockall scores, demographic and clinical characteristics, therapeutic interventions in the form of transfusions, timing of diagnostic and therapeutic endoscopy and hospital stay, to identify various end points including re-bleeding and mortality as well as comparing them with available published data.

Correspondence: Dr. Khus Raj Dewan, Department of Gastroenterology \& Hepatology, College of Medical Sciences-Teaching Hospital, Bharatpur, Chitwan, Nepal. Email: dewansantosh@yahoo.com. Phone: +9779851003162. DOI: 10.3126/jcmsn.v14i4.22031. Article received: 2018-03-11. Article accepted: 2018-10-01. 


\section{MATERIALS AND METHODS}

This study was conducted in the Gastroenterology Unit of College of Medical Sciences Teaching Hospital, Bharatpur, Nepal from January 2012 to December 2014 Two hundred patients presenting with features of acute upper gastrointestinal bleeding were hospitalized randomly irrespective of age, sex or co-morbidities after obtaining written consent. In emergency, hemodynamic assessment was done. Blood transfusion was given when required. Co-morbidities and complications of cirrhosis were managed with the standard protocols. Once the patient was hemodynamically stable, upper GI endoscopy was performed.

Patients were given a complete Rockall score after endoscopy. Specific drug therapy was given depending upon the case. Esophageal variceal ligation (EVL) was done in patients of portal hypertension at the time of doing diagnostic endoscopy. The Child Pugh score was determined in patients with esophageal varices.

Re-bleeding was defined as a separate episode of hematemesis and/or melena, or nasogastric evidence of new bleeding, decrease in haemoglobin level by $2 \mathrm{~g} \%$ occurring after 24 hours of initial presentation or endoscopy. Shock was defined as a systolic blood pressure less than $90 \mathrm{~mm} \mathrm{Hg}$, pulse rate more than 100 per minute. Total hospital stay was defined as the period from time of admission till discharge or death. In hospital mortality was defined as death occurring during hospital stay. Patients were observed in hospital for re-bleed for at least 7-10 days.

To evaluate the applicability of the Rockall scoring system, two groups were created: Group I with Rockall score $\leq 4$ and Group II with score $\geq 5$. The data were analyzed using SPSS ver 20 to assess the calibration of the risk scoring system, $p$ value was determined using the Chi square goodness of fit test.

\section{RESULTS}

This is a hospital based descriptive study, comprising of 200 patients of AUGIB, age ranging from 14 to 90 years with mean $50.43 \pm 17.75$ years. Males were $142(71 \%)$ and $58(29 \%)$ were females with $\mathrm{M}: \mathrm{F}=2.4: 1$. At presentation, 110 patients $(55 \%)$ had both hematemesis and malena, 56 $(28 \%)$ had only malena, 42 patients $(21 \%)$ had shock, $62(31 \%)$ had severe anemia $(\mathrm{Hb}<7 \mathrm{~g} \%)$ and 82 (41\%) had high urea level ( $>45 \mathrm{mg} / \mathrm{dl})$. Comorbidities were present in $89(44.5 \%)$ patients including GI and hepatobiliary (10.5\%), cardiovascular $(6.5 \%)$, respiratory $(5.5 \%)$, renal $(5 \%)$, neurological $(8 \%)$, and miscellaneous $(9 \%)$.

UGI endoscopy was done within 24 hours in 152 (76\%) patients, within 48 hours in $42(21 \%)$ patients and after 48 hours in $6(3 \%)$ patients. EVL was done at the same time in $82(41 \%)$. Child turcottes Pughs $\mathrm{C}$ grading was found in 71 of 80 patients with esophageal varices. Etiology of AUGIB is shown in Figure 1.

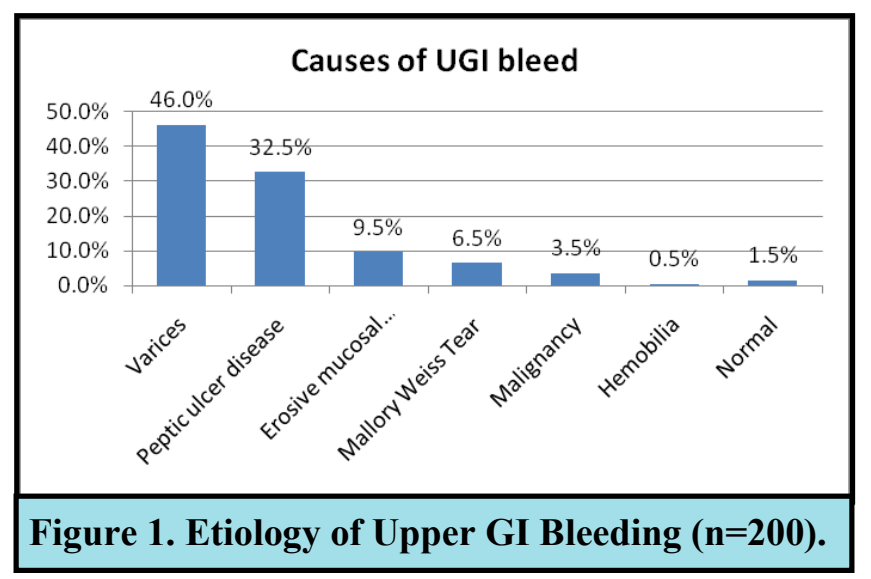

Complete Rockall score ranged from 0 to 9 mean being 4.30+2.19 (Figure 2). Re-bleeding was found in $16(8 \%)$ patients, one with Rockall score $\leq 4$ and

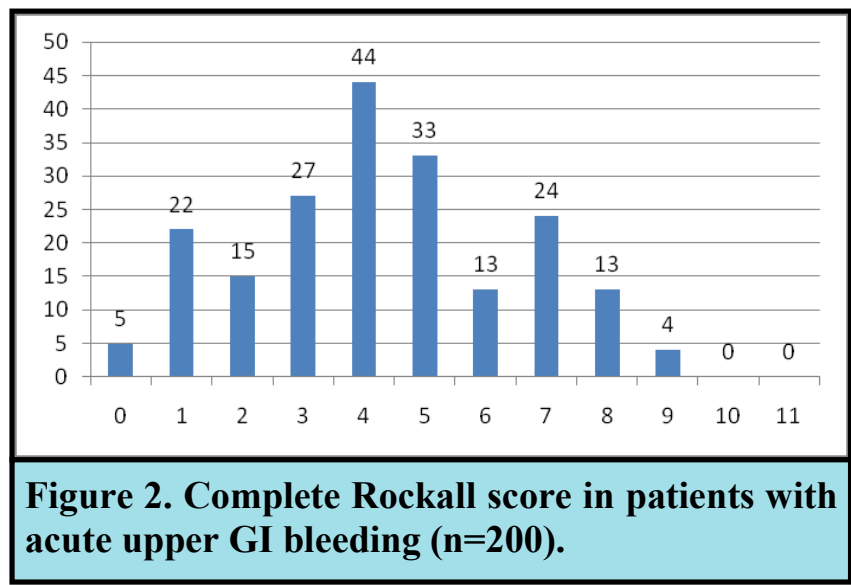

fifteen with Rockall score $\geq 5$. The mean Rockall score for non re-bleeding patients $(n=184)$ was $4.23+2.17$ and that of re-bleeding patients $(n=16)$ was 5.13+2.24. One hundred and eighty eight patients $(94 \%)$ recovered and discharged from the hospital and 12 patients (6\%) expired. The mean Rockall score for surviving patients $(n=188)$ was $4.24+2.18$ while that of expired patients $(n=12)$ was $7.75+1.13$.

Blood transfusion was given to 139 (69.5\%) patients, mean 2.24+3.14 units. EVL was performed in patients with esophageal varices $(n=80)$. The mean 
hospital stay was $6.5 \pm 3.10$ days (Table 1 ). It was obvious that with increasing Rockall score there were increase in the comorbidities, endoscopic interventions, blood transfusions, re-bleeding, inhospital mortality and increase in mean hospital stay (Table 2 ). rebleeding or mortality during hospital stay is very important. Re-bleeding is considered the most important risk factor for mortality and causes five times higher mortality rate compared with patients with initial bleeding. ${ }^{2}$

The mean age is variably reported in different

\begin{tabular}{|lllllllll|}
\hline \multicolumn{7}{|l|}{ Table 1. Showing the distribution of outcomes as per complete Rockall score. } \\
\hline $\begin{array}{l}\text { Rockall } \\
\text { score }\end{array}$ & $\begin{array}{l}\text { No of } \\
\text { patients }\end{array}$ & $\begin{array}{l}\text { Shock at } \\
\text { admission }\end{array}$ & Comorbid & $\begin{array}{l}\text { Bood } \\
\text { Transfusion }\end{array}$ & EVL & Rebleed & Mortality & $\begin{array}{l}\text { Hosp stay } \\
\text { (days) }\end{array}$ \\
$\mathbf{0}$ & 5 & 0 & 0 & $1.0 \pm 1.41$ & 0 & 0 & 0 & $3.0 \pm 2.0$ \\
$\mathbf{1 - 3}$ & 64 & 3 & 26 & $1.65 \pm 1.80$ & 5 & 0 & 0 & $5.41 \pm 1.86$ \\
$\mathbf{4}$ & 44 & 3 & 23 & $2.11 \pm 2.77$ & 22 & 1 & 0 & $6.09 \pm 2.63$ \\
$\mathbf{5}$ & 33 & 1 & 14 & $3.0 \pm 5.29$ & 18 & 7 & 6 & $7.5 \pm 3.72$ \\
$>\mathbf{6}$ & 54 & 7 & 25 & $2.54 \pm 2.28$ & 37 & 8 & 6 & $6.5 \pm 3.47$ \\
\hline
\end{tabular}

Significance at 0.05 level $\left(\chi^{2}\right.$ test $)$

\begin{tabular}{|llllllllll|}
\hline \multicolumn{8}{|l|}{ Table 2. Association of complete Rockall score with re-bleeding and outcome. } \\
\hline $\begin{array}{l}\text { Rockall } \\
\text { Score }\end{array}$ & Rebleed & & $\mathbf{X}^{\mathbf{2}}$ & P value & Outcome & & $\mathbf{X}^{2}$ & P value \\
$\leq \mathbf{4}$ & Yes & No & & & Discharged & Expired & & \\
$\geq \mathbf{5}$ & 1 & 112 & 17.86 & 0.001 & 113 & 0 & 16.58 & 0.001 \\
Total & 15 & 72 & & & 75 & 12 & & \\
\hline
\end{tabular}

Significance at 0.05 level $\left(\chi^{2}\right.$ test $)$

One hundred and thirteen patients (56.5\%) had complete Rockall score $\leq 4$ and 87 (43.5\%) had $\geq 5$. The outcomes were compared between these 2 groups. Rebleeding occurred in $1(0.8 \%)$ patients only in Rockall score $\leq 4$ and there was no mortality, while in Rockall score $\geq 5$ group, 15 patients $(17.2 \%)$ had rebleeding and 12 patients $(13.8 \%)$ expired. Both rebleeding and mortality increased with Rockall score $\geq 5$ as compared with score $\leq 4$. Of 12 expired patients, 10 had rebleeding $(83.3 \%)$, which shows a definite association which were statistically significant $(\mathrm{p}=0.001)$.

\section{Profiles of expired cases:}

In the expired group (6\%), the age ranged from 30 to 70 years with mean age of $49.75 \pm 15.02$ years, males were $58.3 \%$ and females were $41.7 \%$. Their mean Rockall score was $7.75+1.13$. Of the expired patients, 10 of $12(83.3 \%)$ had rebleeding and another 2 died of refractory septic shock. Their mean requirement of blood transfusion was $3.85+1.99$ units. Rebleeding was found to be statistically correlated with mortality in this group $(p=0.001)$. However no statistically significant correlation was found between increasing age $(>40$ years) and mortality $(\mathrm{p}=0.082)$.

\section{DISCUSSION}

Prediction of risk in patients with acute upper gastrointestinal bleeding and early stratification for series. In the present study, mean age was $50.43 \pm 17.75$ years which is higher than the mean age reported from other parts of Nepal, ${ }^{4,5}$ from Sudan $^{6}$ reported mean age of 44.6 years, from India, ${ }^{7,8} 41$ years. Higher mean age of 55 years was reported from West Indies ${ }^{9}$ and 64.4 years has been published in the UK Audit ${ }^{10}$ and 71 years by Vreeburg et al. ${ }^{11}$

The upper gastrointestinal bleeding occurs more frequently in men than women and this relation increases according to age. ${ }^{12}$ Our study showed male predominance i.e. $71 \%$ similar to other parts of Nepal. ${ }^{4,5}$ Some other studies, ${ }^{6,7,8,11,12}$ have also shown male predominance. In Southeast Asian countries, various risk factors like smoking, heavy alcohol consumption, alcoholic liver disease and low socioeconomic status might have some role in the contribution to UGI bleeding.

Several risk scoring systems have been proposed to classify patients into high and low risk groups for rebleeding or mortality based on multivariate analyses. ${ }^{13,18}$ These scoring systems can be used to select low risk patients for early discharge or outpatient treatment, and to select high risk patients for intensive care treatment. The most commonly used risk scoring system is the Rockall score, which was described in 1996 and validated following the analysis of data from a large English audit which incorporates patient age, hemodynamics, co- 
morbidities and endoscopic findings. ${ }^{15}$ Rockall scores can be calculated both before and after endoscopy, but the post-endoscopic Rockall score provides a more accurate risk assessment. Patients at high-risk for re-bleeding receive endoscopic therapy to achieve hemostasis and are subsequently treated with high dose acid suppression to promote the formation of blood clots over the arterial defect responsible for bleeding. Patients with a Rockall score of 0 can be considered for non-admission or early discharge with outpatient follow up. But if the score is above 0 , there is a significant risk of mortality, and endoscopy followed by hospital admission is recommended for a full assessment of bleeding risk. Results have shown that cases that belong to the Rockall score 0-3 have low morality risk of $3.2 \%$, while cases from Rockall score 4-7 classification have $22.8 \%$ mortality rate. ${ }^{15}$

Despite advances in therapy, the case-fatality rate has remained unchanged in the modern era. In our series, 188 patients (94\%) recovered and discharged from the hospital and 12 patients $(6 \%)$ expired. Rao et $\mathrm{al}^{8}$ investigated 1480 patients of upper GI bleeding between 1976 to 1989 where 1080 patients were treated conservatively and a very high mortality rate (162 patients: $15 \%$ ) was noted which was attributed to massive esophageal variceal bleeding with portal hypertension and unavailability of blood in time. Hussein et $\mathrm{al}^{6}$ investigated 238 patients and found a mortality rate of $3.4 \%$. Kashyap et $\mathrm{al}^{16}$ studied 111 patients at Simla (India) and showed an overall mortality rate of $3.6 \%$ and all patients had esophageal variceal bleed. Kaliamurthy et $\mathrm{al}^{8}$ reported a mortality rate of $5.7 \%$. Both UK Audit $2007^{10}$ and Tham et al ${ }^{17}$ had reported $10 \%$ mortality, while Vreeburg reported even higher mortality rate of $14 \%{ }^{11}$

In present study, mean complete Rockall score was $4.30 \pm 2.19$ which was similar to a Korean study by Park et al, ${ }^{18}$ (complete Rockall score $=4$ ), 3.5 \pm 1.8 by Hussain et $\mathrm{al}^{6}$ and another study done by Sanders et al. ${ }^{19}$ Our study shows that higher complete Rockall score $(\geq 5)$ has good predictive value for mortality and in hospital rebleeding. Our results are consistent with those of Wang et $\mathrm{a}^{20}$ who investigated 341 patients with acute UGI bleed and found a positive linear correlation between Rockall scores and patient outcomes in terms of rebleeding, surgery and mortality in the entire patient population ( $\mathrm{X}^{2}=49.29,23.10$ and 27.64 , respectively, $\mathrm{P}=0.001$ ).

We had only 5 patients with 0 score. They required least amount of blood transfusion, least mean hospital stay with no other interventions or any adverse outcome.

In Rockall score 1 to 3 (64 patients) in this series had no adverse outcome though some of them required transfusion and 5 patients needed esophageal variceal band ligation. All of them were discharged after mean $5.41+1.86$ days hospital stay.

In Rockall score $=4$, in this series of 44 patients, only 1 had adverse outcome in the form of rebleed, required blood transfusions but she recovered after gastric variceal ligation and there was no mortality. Therefore we considered this patient group having complete Rockall score $0-4(\mathrm{n}=113)$ as a lower or lesser risk group. In Rockall score $\geq 5(\mathrm{n}=87)$, there was more requirement of transfusions with more comorbidities, increase number of EVL (63.2\%), adverse outcome, rebleed in $15(17.2 \%)$ patients, mortality in $12(13.8 \%)$ patients and increased hospital stay. These difference in adverse outcomes when compared with patients having Rockall score $\leq 4$ were found to be statistically significant $(p=0.001)$. We further compared Rockall score in expired and discharged group. In the discharged group, 113 patients $(56.5 \%)$ had Rockall score $\leq 4$ and 75 patients (37.5\%) had Rockall score $\geq 5$. In the expired group, all 12 patients had Rockall score $\geq 5$. There were significant correlations between high Rockall scores $(\geq 5)$ and the occurrence of rebleeding $(\mathrm{p}=0.001)$ and mortality $(\mathrm{p}=0.001)$ in the entire patient population.

While predicting the outcome for their series of 102 cases of acute UGI bleed, Tham et al,${ }^{17}$ reported no adverse outcome and nil requirement of blood transfusion in clinical Rockall score 0 patients and in those with 1 to 3 score none had any adverse outcome, although $29 \%$ patients required blood transfusion while those with score $>3$, adverse outcomes found were rebleeding in $21 \%$, surgery in $5 \%$ and death in $10 \%$. Rockall et $\mathrm{al}^{3}$ reported adverse outcome in the form of rebleed $(4.3 \%)$ and mortality $(0.1 \%)$ in patients with Rockall score $<2$ in their first National Audit and later in the 2007 National Audit reported re-bleeding in 3.5 to $6.3 \%$, mortality up to $1.4 \%$ and $27 \%$ received transfusion in patients with complete Rockall score $<2$ and the adverse outcomes increased with higher complete Rockall score.

In a series of 395 patients of non variceal bleed, Gleeson et $\mathrm{al}^{21}$ reported no adverse outcome in their patients with Rockall score $<3$ while those with Rockall score $>4$ had $0.76 \%$ rebleed and $2.02 \%$ 
mortality. In a retrospective study of 222 patients, Bessa et $\mathrm{al}^{22}$ reported rebleed in $18.4 \%$ patients (Rockall score $<5$ ) with nil mortality, but those with Rockall score $>6$ had $25.2 \%$ rebleed and mortality in $9 \%$.

In the series of Hussein et $\mathrm{al}^{6} 3.8 \%$ mortality was found in Rockall score 1 to 10 with $7.6 \%$ rebleeding. Jairath et $\mathrm{al}^{23}$ from UK reported mean clinical Rockall score of 2.65 in their series of patients undergoing endoscopy for AUGIB (no 5,004 of 6,749 ) with overall rebleeding in $13 \%$ and mortality in $7 \%$, requiring therapeutic endoscopy in $24 \%$ and red cell transfusion in $39 \%$.

Vreeburg et al, ${ }^{11}$ investigated 1000 cases and reported rebleeding in $16 \%$ patients and mortality rate was $14 \%$. They concluded that the risk scoring system developed by Rockall is a clinically useful scoring system for stratifying patients with acute UGIB into high and low risk categories for mortality. For the prediction of rebleeding, however, the discriminative performance of this scoring system was found to be unsatisfactory. Possibly, other risk factors are more important for the prediction of rebleeding ${ }^{13}$ than for the prediction of mortality, ${ }^{18}$ or the risk factors should be weighted differently.

\section{Identification of patients with lower risk and higher risk of poor outcomes}

The present series had $69(34.5 \%)$ patients having Rockall score 0-3, inclusive of 13 patients of Mallory Weiss tear and 3 patients with normal endoscopic finding. Some of them required blood

\section{REFERENCES}

1. Yavorski RT, Wong RK, Maydonovitch C, Battin LS, Furnia A, Amundson DE. Analysis of 3,294 cases of upper gastrointestinal bleeding in military medical facilities. Am J Gastroenterol. 1995; 90:568-73.

2. Forrest JA, Finlayson ND, Shearman DJ. Endoscopy in gastrointestinal bleeding. Lancet. 1974;2:394-7.

3. Rockall TA, Logan RF, Devlin HB, Northfield TC. Risk assessment after acute upper gastrointestinal haemorrhage. Gut.1996; 38: 316-21.

4. Gurung RB, Joshi G, Gautam N, Pant P, Pokhrel B, Koju R et al. Upper gastro-intestinal bleeding: Aetiology and demographic profile based on endoscopic examination at Dhulikhel Hospital, Kathmandu University Hospital. Kathmandu University Medical Journal. 2010; transfusion, few had comorbidities, only 5 (2.5\%) required endoscopic intervention for band ligation of esophageal varices and least hospital stay. None had rebleed or mortality. All recovered and were discharged. This group may be considered as having low risk and fit for early discharges.

Those with Rockall score $4(n=44)$ were considered as of mild risk as only $1(0.5 \%)$ patient had rebleed, no mortality few comorbidities $(11.5 \%)$, requirement of blood transfusion was less with slightly extended hospital stay, though endoscopic intervention was done in $22(11 \%)$. All recovered and were discharged. However, 87 (43.5\%) patients having Rockall score $\geq 5$ were considered as of higher risk as $15(17.24 \%)$ of them had rebleeding, 12 (13.79\%) expired, $24(27.58 \%)$ had shock at admission, comorbidities in the majority $(54.02 \%)$, endoscopic interventions done in 55(63.2\%), required more blood transfusion and hospital stay for a longer period.

\section{CONCLUSIONS}

Acute UGI bleeding is a medical emergency and risk scores are of critical importance. Complete Rockall score is the most widely used postendoscopy score which predicts mortality as well as in-hospital rebleeding. Patients with complete Rockall score $\geq 5$, having cirrhotic portal hypertension with bleeding esophageal varices, Child Pughs C, multiple comorbidities and rebleeding are the most vulnerable group for fatal outcome. Urgent, appropriate hospital management definitely helps to reduce morbidity and mortality.

\section{8:208-11.}

5. Bhattarai J, Acharya P, Barun B, Pokharel S, Uprety N, Shrestha NK. Comparison of endoscopic findings in patients from different ethnic groups undergoing endoscopy for upper gastrointestinal bleed in eastern Nepal. Nepal Med Coll J. 2007; 9(3):173-5.

6. Hussein M S, MAM I, Abdulaziz A S, Abdelmagid M M. Rockall score of the acute upper gastrointestinal bleeding patients the experience in Sudan. Sudan JMS. 2009; 4: 232-5.

7. Anand C. S., Tandon B. N. \& Nundy S. The causes, management and outcome of upper gastrointestinal haemorrhage in an Indian hospital. British Journal of Surgery. 1983;70: 209 -11 .

8. Rao THSG, Pande GK, Sahni P, Nundy S. The management of uppe gastrointestinal haemorrhage in a tropical country. Archives of 
Dewan et al. Complete Rockall Score in Predicting Outcomes in Acute Upper Gastrointestinal.

Emergency Medicine. 1991; 8: 169-76.

9. Kaliamurthy M, Lee MG, M Mills, Murphy T. Upper Gastrointestinal Bleeding: A Jamaican Perspective. West Indian Med J. 2011; 60 (3): 289-92.

10. Hearnshaw SA, Logan RFA, Lowe D, Travis SPL, Murphy MF, Palmer KR. Acute upper gastrointestinal bleeding in the UK: patient characteristics, diagnoses and outcomes in the 2007 UK audit. Gut 2011;60:1327-35.

11. Vreeburg EM, Terwee CB, Snel P, Rauws EA, Bartelsman JF, Meulen JH, Tytgat GN. Validation of the Rockall risk scoring system in upper gastrointestinal bleeding. Gut. 1999; 44:331-5.

12. Longstreth GF, Feitelberg SP. Successful outpatient management of acute upper gastrointestinal hemorrhage: use of practice guidelines in large patients series. Gastrointest Endosc. 1998; 47:219-22

13. Saeed ZA, Ramirez FC, Hepps KS, et al. Prospective validation of the Baylor bleeding score for predicting the likelihood of rebleeding after endoscopic hemostasis of peptic ulcers. Gastrointest Endosc. 1995;41:561-5.

14. Enns RA, Gagnon YM, Barkun AN, Armstrong D, Gregor JC, Fedorak RN. Validation of the Rockall scoring system for outcomes from nonvariceal upper gastrointestinal bleeding in a Canadian setting. World J Gastroenterol. 2006; 12: 7779-85.

15. Rockall TA, Logan RF, Devlin HB, Northfield TC. Influenc- ing the practice and outcome in acute upper gastrointestinal haemorrhage. Steering Committee of the National Audit of Acute Upper Gastrointestinal Haemorrhage. Gut 1997; 41: 606-11.

16. Kashyap R, Mahajan S, Sharma B et al. Clinical Profile of Acute Upper Gastrointestinal
Bleeding at Moderate Altitude. JIACM. 2005; 6 (3): 224-8.

17. Tham TCK, James C, Kelly M. Predicting outcome of acute non-variceal upper gastrointestinal haemorrhage without endoscopy using the clinical Rockall Score. Postgrad Med J. 2006;82(973): 757-59.

18. Park SM, Yeum SC, Kim BW, Kim JS, Kim JH, Sim EH, et al. Comparison of AIMS65 Score and Other Scoring Systems for Predicting clinical Outcomes in Koreans with Nonvariceal Upper Gastrointestinal Bleeding. Gut Liver. 2016;10 (4):526-31.

19. Sanders DS, Carter MJ, Goodchap RJ, Cross SS, Gleeson DC, Lobo AJ. Prospective validation of the Rockall risk scoring system for upper GI hemorrhage in subgroups of patients with varices and peptic ulcers. Am J. Gastroenterol. 2002; 97: 630-5.

20. Wang CY, Qin J, Wang J, Sun CY, Cao YT, Zhu DD. Rockall score in predicting outcomes of elderly patients with acute upper gastrointestinal bleeding. World J Gastroenterol. 2013; 19: 346672.

21. Gleeson F, Clarke E, Lennon J et al. Outcome of accident and emergency room triaged patients with low risk non-variceal upper gastrointestinal haemorrhage. Ir Med J. 2006;99: 114-17.

22. Bessa X, O'Collaghan, Ballesta B, Nieto $M$, Seoane A, Panades A et al. Applicability of the Rockall Score in patients undergoing endoscopeic therapy for upper gastrointestinal bleeding. Dig Liver Dis. 2006; 38(1): 12-7.

23. Jairath V, Kahan B C, Logan R F. et al. Mortality from acute upper gastrointestinal bleeding in the United Kingdom: does it display a "weekend effect"? Am J Gastroenterol. 2011;106:1621-28.

Citation: Dewan KR, Patowary BS, Bhattarai S, Shrestha G. Complete Rockall Score in Predicting Outcomes in Acute Upper Gastrointestinal Bleeding. JCMS Nepal. 2018;14(4):178-83. 